\title{
Hacia el centro: el PT y el gobierno de Lula en Brasil
}

\section{Towards the centre: PT and Lula's government in Brazil}

\section{Cláudio Gonçalves Couto}

Cláudio Gonçalves Couto es cientista político, professor do Departamento de Gestão Pública da Fundação Getúlio Vargas de São Paulo, Brasil.

E-mail: claudio.couto@fgvsp.br

\section{resumen}

El gobierno de Lula representó la culminación de un proceso de circulación de elites en Brasil: llegó al poder nacional con un conjunto de liderazgos oriundos de los sectores hasta entonces excluidos del acceso directo al gobierno del país. Además, se consolidó una bipolarización partidaria centrista, con el PT a la centro-izquierda y el PSDB al centro, pero atrayendo los sectores sociales más conservadores, privados de una derecha partidaria capaz de representarlos en las disputas del gobierno nacional.

\section{palabras clave}

política brasileña / sistema de partidos / izquierda y derecha / gobierno de Lula

\section{summary}

Lula's administration represented the ultimate step of a process of circulation of elites in Brazil: the national power was gathered by a group of leaders who came from the social sectors historically excluded from the direct access to the country's government. In addition, it was consolidated a centrist bipolarization between PT and PSDB, the former at the center-to-the-left and the last one at the center, however attracting the most conservative social sectors who were deprived of a partisan right that was capable of represent them in the national government political contests.

\section{keywords}

Brazilian politics / party system / left and right / Lula's administration 
Muitos pontos poderiam ser considerados numa análise crítica dos anos da presidência de Luis Inácio Lula da Silva: um realinhamento do sistema partidário, com a bipolarização nacional entre o Partido dos Trabalhadores (PT) e o Partido da Social Democracia Brasileira (PSDB), os demais partidos representando satélites desse movimento; a ascensão aos estratos inferiores da classe média de um largo contingente de brasileiros que durante décadas viveram em condições de pobreza; a projeção inaudita do Brasil no cenário internacional (a partir do protagonismo do presidente e de ações pouco afeitas à nossa tradicional postura de perfil baixo); a retomada de níveis satisfatórios de crescimento econômico etc. Ater-me-ei aqui a apenas alguns deles: (1) a significativa alternância dos grupos sociais que ganharam acesso ao centro do poder nacional (2) à guinada nos termos do debate político nacional, acarretando uma concepção política desvinculada de padrões morais tradicionais e (3) uma reorientação de todo o sistema partidário rumo ao centro, possibilitando a construção de uma ampla coalizão governativa.

A chegada do ex-líder sindical Luiz Inácio Lula da Silva à Presidência da República, em 2002, marcou o culminar, no Brasil, do longo processo de "circulação de elites", segundo a concepção do economista e sociólogo italiano Vilfredo Pareto. No seu dizer, a circulação de elites é um lento fenômeno de transformação dos grupos superiores de uma sociedade, refletindo o conjunto de suas mudanças. Por esse processo, em vez de rupturas revolucionárias -que ocorreriam em decorrência da incapacidade das velhas elites de atualizar-se mediante a absorção dos elementos emergentes-, o que se verifica é a mescla entre os novos e velhos setores dirigentes. Assim, pela absorção paulatina dos indivíduos mais notáveis (os líderes) das camadas sociais subalternas, as antigas elites são capazes de perpetuar-se em chave lampedusiana, ou seja, "mudando para que nada mude". ${ }^{1}$

Uma forma de encarar essa atualização conservadora é supor que de fato nada mudou, tendo-se apenas cooptado os líderes das classes subalternas de maneira a mantê-las em sua posição de mansa inferioridade. Numa tal perspectiva, essa incorporação dos antes excluídos seria o preço que as classes dominantes pagariam para manter-se por cima, sem de fato ceder nada de relevante. Essa seria a perspectiva notada por Antônio Gramsci e seus seguidores, na concepção de "revolução passiva". ${ }^{2} \mathrm{O}$ curioso é que Pareto, ele mesmo um conservador, reconhecia na incorporação dos novos elementos uma condição necessária à revigoração da classe dominante. Esta, ao mesmo tempo em que absorve os oriundos dos setores emergentes (a antiga não-elite), livra-se de seus membros mais degenerados. Trata-se, assim, de um processo de reciclagem por meio do qual permanecem apenas aqueles membros da velha elite capazes de adaptar-se aos novos tempos. Para esses, e apenas para eles, o que "nada muda" é a sua condição de componentes da elite dominante, embora mudem seus companheiros de viagem -alguns chegam, outros caíram pelo caminho-e, como consequência disso, muda também o rumo a ser seguido.

É em virtude desse último aspecto da mudança que se pode afirmar que a transformação promovida pela atualização conservadora da circulação de elites não é tão irrelevante quanto poderia parecer à primeira vista. O exemplo clássico pen- 
sado por Pareto é a Inglaterra, que promoveu a circulação de elites mediante a mescla entre a burguesia ascendente e uma aristocracia que optou pelo seu próprio aburguesamento. Não apenas os nobres britânicos passaram a conviver com outro grupo social, ao qual anteriormente rejeitavam, mas também assumiram muito de seu modo de ser - tendo sido a recíproca inteiramente verdadeira. Os novos caminhos a serem seguidos, contudo, foram os ditados pelo grupo ascendente, rumo a um poderoso capitalismo. Por isso mesmo, é tão notável que a Grã-Bretanha tenha conjuminado a síntese entre a economia capitalista mais avançada do planeta e a preservação mais efetiva das tradições nobiliárquicas - um cenário muito diverso do estabelecido na França, onde a resistência da nobreza à emergência burguesa levou o país ao cadafalso da Revolução; ali, as elites não circularam.

A lenta e relativamente tranquila transição social e política brasileira, na medida em que possibilitou que mesmo os segmentos politicamente mais radicais fossem paulatinamente incorporados à disputa do poder nacional, facilitou que também experimentássemos a nossa circulação de elites. Um dos reflexos mais visíveis da mistura de classes no cume do Estado é a heterogeneidade sociopolítica da coalizão de governo: convivem antigos militantes da esquerda clandestina, antigos apoiadores do regime militar, políticos direitistas tradicionais, sindicalistas da geração do final dos anos 70 e começo dos 80 , acadêmicos, empresários e lideranças de movimentos sociais. $\mathrm{O}$ que pode parecer à primeira vista mera inconsistência ideológica é, na verdade, a face mais aparente do processo de mescla sociopolítica do qual Lula é a liderança mais notável.

O elemento distinguido do fenômeno histórico da liderança de Lula decorre de duas características, ambas convergindo na política democrática. Em primeiro lugar, está sua capacidade de chefiar a heterogênea coalizão resultante do processo de circulação de elites, conferindo-lhe coesão política. Por meio do voto, mas também mediante o sucesso de suas ações de governo na obtenção da aprovação popular, o líder político proveniente dos setores subalternos obtém a legitimidade necessária para congregar setores díspares que, num passado nem tão distante, mostravam-se incapazes de coabitar. Em segundo lugar, está o fato de que, num país como o Brasil, por decênios figurando entre os mais desiguais do planeta, a chegada às chefias de Estado e governo de uma liderança política originada dos estratos sociais mais baixos é, por si só, bastante significativa.

Não casualmente, essa mesma liderança promoveu seu ingresso na cena política nacional a partir de uma experiência pessoal de ascensão social: Lula saiu da condição de pau-de-arara para ingressar, como trabalhador formal, no setor industrial mais desenvolvido do centro-sul do país; algum tempo depois se converteu justamente na liderança mítica desse mesmo setor avançado, vocalizando as demandas de uma parcela da população que portava, ao mesmo tempo, a modernidade econômica e a subalternidade política e social. A consequência prática imediata (porém não inevitável) dessa atuação foi a estruturação de uma agremiação partidária que, entrando na cena político-eleitoral, abriu espaço ao ingresso dos emergentes no ambiente governamental e representativo. A partir desse momento, num país que se democratizava, seria muito difícil negar-lhes legitimidade, caso se mostras- 
sem bem-sucedidos; foi a política democrática que abriu espaço para o ingresso, no âmbito estatal, das lideranças oriundas do processo de modernização social. Noutras palavras, foi a consolidação da democracia que permitiu a concretização da circulação das elites.

Quanto às consequências políticas concretas, esse processo de circulação acarretou uma inflexão das políticas governamentais e do discurso presidencial na direção dos setores subalternos mediante políticas de renda, tanto de caráter distributivo (como o Bolsa Família), como redistributivo (como o aumento real do salário mínimo). Tais políticas, associadas à estabilidade monetária e à retomada do crescimento econômico, com o decorrente aumento do emprego formal, também impactaram positivamente a renda dos setores mais pobres. Isso contribuiu para inverter a base de sustentação político-eleitoral de Lula (ainda que não do PT), alavancando muito fortemente as popularidades do governo e do presidente (assim como sua votação) entre os cidadãos de (cada vez menos) baixa-renda. Desse modo, se até 2002 Lula e o PT eram mais fortemente apoiados pelos trabalhadores sindicalizados e pelas classes médias escolarizadas, a partir de 2006, embora o partido tivesse mantido sua base tradicional, o presidente seguiu rumo aos setores sempre mais marginalizados. André Singer (2009) analisa de forma esmerada esse processo num artigo que logo se tornou célebre, apontando a capacidade do líder Lula galvanizar o apoio dos setores historicamente excluídos social, política e economicamente no Brasil (o "subproletariado"), enquanto seu partido ainda mantinha as bases às quais tradicionalmente se vinculou. ${ }^{3}$

Desse modo, a direita tradicional, que já carecia de um representante dotado de densidade eleitoral nas disputas nacionais, viu-se definitivamente deslocada das possibilidades de construir autonomamente um projeto próprio de poder no plano federal. O antigo Partido da Frente Liberal (PFL), rebatizado como Democratas (DEM), única agremiação de direita que ainda conservava algum grau de organicidade social, consistência ideológica e capacidade de atuação nacional, foi impiedosamente transformado numa força secundária. Isto é evidenciado pelo seu quase que completo alijamento de governos estaduais e locais importantes, assim como seu enfraquecimento parlamentar no plano nacional. Nas disputas presidenciais, o DEM tornou-se uma mera força auxiliar do principal opositor do PT no plano nacional, o Partido da Social Democracia Brasileira, o PSDB. Esse soçobrar da direita partidária ideológica brasileira é o que talvez explique como o velho PDS, herdeiro da ARENA do regime militar, outrora programático, converteu-se num partido de adesão fisiológico, prestando-se até mesmo a dar sustentação a um governo liderado pela principal agremiação de esquerda do país. Fechou-se assim o círculo da transformação de nossas elites governantes.

Embora seja fácil compreender a guinada do eleitorado mais pobre rumo a Lula em função de seus ganhos econômicos, não é este mesmo fator o que explica a debandada de um grande contingente das classes médias. Apesar de existirem os discursos de viés mais claramente reacionário, como os que tacham de "assistencialista" qualquer política de distribuição de renda (apelidando de "bolsa-esmola" uma política enaltecida até mesmo pelos técnicos economicamente ortodoxos do 
Banco Mundial), o fator determinante para o afastamento dos setores médios foi a crise moral vivida pelo PT - sobretudo a partir do escândalo do assim chamado "mensalão", entre 2005 e $2006 .{ }^{4}$ Aquele que outrora figurara como o "partido da ética na política", apresentando-se ao eleitorado como o "grilo falante" do país, viu-se enredado num escândalo para o qual a melhor explicação encontrada foi afirmar que nada mais fizera do que agir da mesma forma que todos os demais. Ora, mas era exatamente aí que residia o problema: pela sua reputação -demoradamente construída- de algoz moral da nação, o PT não poderia permitir-se agir como os demais. Ao fazer isso, despencou vertiginosamente do altíssimo pedestal que havia erigido para si mesmo.

A revelação de adesão aos piores costumes nacionais, feita pela boca do próprio Lula, contribuiu para o desencantamento moral da política brasileira, desnudada aos cidadãos principalmente pela prestimosa e sardônica verve do deputado federal Roberto Jefferson, presidente do Partido Trabalhista Brasileiro (PTB), um dos principais aliados do governo Lula na seara conservadora de sua base parlamentar. Mas, se tais traços eram realmente tão característicos da política nacional, só poderia mesmo ser ilusório o espaço que, num certo momento, pareceu abrir-se à oposição: o da "ética na política". Tal senda, como se poderia esperar, rapidamente esvaiu com o surgimento de outros "mensalões", que solaparam um a um os principais partidos nacionais que ainda gozavam de algum crédito e capacidade de atuar como protagonistas no plano nacional - o PSDB e o PFL (já em sua surrada roupa nova, de DEM).

Desse modo, não sobrou muito espaço para mistificações éticas construídas em torno da busca de um "partido dos puros", e a política nacional foi reduzida a suas devidas (e mais realistas) proporções: um âmbito da vida social no qual a distinção entre os atores relevantes não se dá entre os "éticos" e os "não éticos", mas sim entre os que defendem políticas de tipo diverso, ou simplesmente disputam o poder de Estado. Nessa hora, diante da perturbadora desaparição das referências morais, os que mais atavicamente se punham contra ou a favor de seus antigos grupos de referência, logo encontraram subterfúgios retóricos para justificar a manutenção das posições políticas: postaram-se contra o "neoliberalismo" (esse que, no Brasil, foi sem nunca ter sido) e contra o "aparelhismo" (aquele que só existe quando é feito pelos outros). Mas esses biombos são mais facilmente transponíveis do que as velhas ilusões éticas.

Pode-se dizer que os sucessivos escândalos da era Lula (tanto os que atingiram petistas como os que respingaram em seus opositores) tiveram um curioso efeito de saturação: guindaram o Brasil a uma política pós-ética, bem menos ingênua do que aquela que muitos (sobretudo eleitores petistas) acalentaram durante muito tempo. Nesse novo cenário, as preferências políticas passaram a apresentar-se de forma mais clara (como o que de fato são), talvez até mesmo permitindo que esquerda e direita voltem a mostrar-se de forma mais nítida - mesmo sem estarem hoje tão distantes uma da outra, como já estiveram no passado. Este, a propósito, é um aspecto que deve ser analisado com mais vagar, observando-se a coalizão que -ao longo de oito anos- deu sustentação parlamentar ao governo Lula. 


\section{A coalizão de Lula e a guinada rumo ao centro}

Luís Inácio Lula da Silva foi eleito em 2002 por uma aliança até então incomum para os padrões petistas, normalmente marcados pela agregação de diferentes agremiações exclusivamente do campo da esquerda. Neste figurino "clássico", constavam o Partido Comunista do Brasil (PC do B), principal aliado do PT desde as eleições municipais de 1988; o Partido Socialista Brasileiro (PSB), que indicou o primeiro candidato vice-presidencial de Lula em 1989 (José Paulo Bisol) e, eventualmente, o Partido Democrático Trabalhista (PDT), que ora se aproximava do PT, ora dele se afastava, ao sabor dos caprichos idiossincráticos de seu caudilho, Leonel Brizola, que inclusive figurou como candidato a vice-presidente de Lula nas eleições de 1998. A significativa mudança de 2002 foi marcada pela coligação com o Partido Liberal (PL), com a consequente indicação do candidato vice-presidencial - o megaempresário do setor têxtil e senador por Minas Gerais, José de Alencar.

Às demonstrações de espanto com a indicação de Alencar e a aliança com os "liberais", Lula replicava que, daquela vez, desejava ganhar as eleições, e não apenas competir novamente para acabar derrotado. Em suas experiências eleitorais anteriores no plano nacional o PT marcou-se pela crítica acerba dos governos do dia e por um discurso claramente à esquerda. Em 1989, atacava o malogrado governo Sarney e os partidos que lhe deram sustentação (PMDB e PFL), o que lhe rendeu a ida para o segundo turno, reforçou sua reputação de principal referência de oposição (a o que quer que seja) no plano nacional, mas também facilitou as acusações de radicalismo que lhe foram desferidas pelo conservador Fernando Collor de Mello. Em 1994, acusava o bem-sucedido plano de estabilização monetária de Fernando Henrique Cardoso, o Plano Real, de ser uma mera manobra eleitoreira, fadada ao mesmo fracasso de muitos planos anteriores - como, por exemplo, o Plano Cruzado de 1986. A maioria do eleitorado não acreditou nas críticas petistas e votou massivamente em Fernando Henrique Cardoso, que venceu no primeiro turno. Em 1998, continuou a criticar o Plano Real, apesar de seu já evidenciado sucesso na estabilização monetária. Por isto, direcionou as críticas principalmente às reformas do Estado -em particular as privatizações- realizadas por Fernando Henrique. Novamente perdeu as eleições no primeiro turno para FHC, cuja campanha se escorou na necessidade de manter a estabilidade econômica, para o quê a vitória de Lula seria uma ameaça. Assim, o petista foi derrotado continuando a reforçar sua reputação de empedernido oposicionista a tudo o que mais existe e for governo.

Finalmente, em 2002, Lula optou por uma estratégia que ele mesmo chamou de "Lulinha Paz e Amor", referendada depois pela célebre "Carta ao Povo Brasileiro", na qual afirmava seu compromisso com a estabilidade monetária, a responsabilidade fiscal, o respeito aos contratos e o bom relacionamento com o empresariado. Com tal estratégia, era mesmo natural ter um vice-presidente oriundo do grande capital nacional, representando um contraponto ao operário e ex-líder sindical encarnado por Lula. Para lustrar ainda mais sua imagem, tornando-a mais palatável aos setores da sociedade que antes os rejeitavam, Lula e o PT contrataram o mais 
célebre dos homens de marketing eleitoral no Brasil, Duda Mendonça, que já havia sido responsável, alguns anos antes, pela reabilitação política do antes rejeitadíssimo político conservador Paulo Maluf, elegendo-o prefeito de São Paulo. Sob a batuta de Mendonça, Lula ganhou ares ainda mais sóbrios, passou a trajar-se de forma mais elegante, aproveitou-se do ar mais sério que lhe era conferido pela barba grisalha e, desta forma, venceu pela primeira vez a corrida presidencial.

Desta feita, as críticas ao governo anterior ganharam tons mais amenos, seguindo a máxima cunhada por Mendonça segundo a qual "quem bate perde". A principal tônica do discurso lulista naquela eleição foi enfatizar a necessidade de criarem-se novos empregos; o número brandido foi de 10 milhões de novos postos de trabalho, gerando críticas do candidato tucano de então, José Serra, que acusava o petista de demagogia. Contudo, talvez mais importante do que a viabilidade dos números era a mudança de significado que o discurso centrado nos empregos representava no discurso petista. Em vez de uma fala claramente negativa, de repúdio ao governo que terminava, o petista optou por um discurso afirmativo - o da necessidade de avançar em relação ao existente, ainda que sugerindo claramente que a administração do PSDB havia sido malsucedida na tarefa de promover o crescimento econômico e os consequentes novos empregos. Como a reputação de oposição já havia sido forjada pelo PT e por Lula nas três derrotas anteriores (e na própria atuação do partido ao longo dos anos), não ficava para o eleitor qualquer dúvida quanto ao fato de que eles encarnavam a real alternativa mudancista num cenário de baixíssima popularidade do governo que acabava.

O resultado foi a ida de Lula para o segundo turno numa eleição bastante disputada, em que figuraram quatro candidatos relevantes à Presidência da República: além do candidato petista e de Serra, também Anthony Garotinho, ex-governador do Rio de Janeiro, pelo Partido Socialista Brasileiro (PSB), e Ciro Gomes, exgovernador do Ceará e ex-ministro da Fazenda, pelo Partido Popular Socialista (PPS). Note-se que todos eram políticos de esquerda ou centro-esquerda; a direita foi a grande ausente das eleições de 2002. ${ }^{6}$ Notava-se já naquela eleição um enfraquecimento da direita de caráter mais programático, representada até pouco tempo antes pelo PFL e pelo Partido Democrático Social (PDS) e seus sucedâneos (PPR, PPB e PP) - ambos herdeiros da antiga Aliança Renovadora Nacional (ARENA), agremiação de sustentação da ditadura militar. Este enfraquecimento da direita, aliás, é um fenômeno que merece uma breve análise.

A ausência dos candidatos conservadores no pleito presidencial de 2002 se deve primeiramente (ainda que isto não seja necessariamente o mais importante) a dois fatores de ordem conjuntural, que tiveram, entretanto, efeitos de mais longo prazo. O primeiro deles foi a débâcle da pré-candidatura de Roseana Sarney, potencial postulante presidencial do PFL após o distanciamento desse partido do governo Fernando Henrique Cardoso. Uma ação da Polícia Federal promovida com bastante estardalhaço descobriu um cofre abarrotado de dinheiro vivo numa empresa da família Sarney; a divulgação pela mídia das fotos de pilhas de notas de reais dizimou as chances da até então promissora candidata, deixando o PFL sem um nome forte para a disputa presidencial. Como tanto a família Sarney como o PFL 
atribuíam a José Serra a urdidura da ação policial, isto levou ao rompimento do partido com o PSDB, que disputou aquelas eleições coligado ao centrista PMDB, afastando-se momentaneamente da direita partidária.

O segundo fator conjuntural foi a decisão do Supremo Tribunal Federal (STF) de confirmar o entendimento do Tribunal Superior Eleitoral (TSE), de "verticalização" das coligações eleitorais naquele ano. ${ }^{7} \mathrm{Na}$ interpretação da corte eleitoral, o caráter nacional dos partidos políticos previsto na Constituição Brasileira implicava que as coligações eleitorais nas disputas estaduais deveriam estar de acordo com o padrão estabelecido na disputa nacional, de modo que partidos integrantes de coalizões eleitorais adversárias na eleição presidencial não poderiam aliar-se em coligações nos Estados. ${ }^{8}$ Com isto, muitas agremiações que tinham estratégias de alianças diferenciadas nos vários Estados da Federação brasileira viram-se inibidas a integrar uma coligação no plano nacional, pois isto lhes restringiria significativamente a liberdade de coligarem-se das formas que lhes fossem as mais eficientes em cada uma das unidades federativas. Assim, muitos partidos -sobretudo do campo conservador-abdicaram de disputar as eleições presidenciais, coligada ou isoladamente, de modo a poder aliar-se como bem entendessem no plano subnacional. Noutras palavras, a tentativa do judiciário de promover a nacionalização dos partidos teve exatamente o efeito oposto, estadualizando-lhes.

Foi esta, por exemplo, a opção do Partido Progressista Brasileiro (PPB), denominação adotada à época pelo antigo PDS. Esta agremiação foi, durante quase duas décadas, o principal partido do conservadorismo brasileiro, rivalizando a partir de 1985 com o PFL, que, aliás, surgiu como uma dissidência sua e lhe ultrapassou em importância. Entre 1985 e o final dos anos 1990, o partido tornou-se muito dependente da liderança do político paulista Paulo Maluf, seu candidato presidencial em duas ocasiões e seu potencial postulante presidencial sempre, até então. Com o naufrágio de sua liderança política após a catastrófica administração na Prefeitura de São Paulo de seu pupilo, Celso Pitta (a cujo sucesso ele hipotecou sua própria carreira política), o PPB fragilizou-se bastante. Sua decadência se deu tanto na política paulista como no cenário nacional, tornando-se apenas mais um dentre os diversos partidos repletos de políticos pragmáticos, adeptos das práticas mais tradicionais da política profissional no Brasil, sem grandes veleidades ideológicas e dispostos a dar sustentação a qualquer governo que lhes agracie com prebendas estatais, seja na forma de cargos públicos, seja na forma de verbas destinadas a suas bases eleitorais ou seus financiadores de campanha. Ora, tendo o PPB se tornado uma agremiação com estas características, pouco teria a ganhar disputando as eleições presidenciais, nas quais não teria chances significativas. Melhor para a agremiação foi confinar-se às disputas estaduais, o mais das vezes apoiando candidatos a governador de outros partidos cujos governos depois viria a integrar.

Para além dos fatores conjunturais das eleições de 2002, o que também contribuiu de forma decisiva para esse esmaecimento da direita partidária no Brasil foi a bipolarização entre PT e PSDB no plano nacional - a qual, em certa medida, tem-se repetido em diversas unidades federativas. Lula e o PT saíram derrotados da eleição de 1989, mas se posicionaram de imediato como os postulantes naturais 
da oposição mais frontal a Collor, e de esquerda, no pleito de 1994. De fato, no início daquele ano, Lula figurava como o favorito nas pesquisas de intenção de voto à Presidência da República, sendo apenas ultrapassado por Fernando Henrique Cardoso, do PSDB, quando o Plano Real começou a dar mostras de que era efetivamente capaz de derrotar a inflação. Para vencer aquelas eleições e garantir uma base de sustentação sólida para seu governo, Cardoso forjou uma aliança com o conservador PFL, a qual se repetiria em 1998.

Deste modo, o PSDB, nascido na centro-esquerda e tendo inclusive apoiado Lula contra Collor no segundo turno de 1989, inflectiu-se à direita, chegando ao centro. Já o PFL, oriundo da direita, inflectiu rumo ao centro já em seu nascimento, como Frente Liberal, em 1984, quando apoiou a candidatura de oposição nos estertores da ditadura militar. Em 1994 deu um novo passo nessa direção, chegando à centro-direita e figurando, durante oito anos, como uma poderosa força auxiliar do PSDB no governo Cardoso. Tão poderoso era o PFL nesse contexto que em duas ocasiões lideranças suas emergiram como potenciais candidatos à sucessão de FHC. A primeira foi com a ascensão política de Luís Eduardo Magalhães, filho do oligarca baiano Antônio Carlos Magalhães e presidente da Câmara dos Deputados durante o primeiro mandato de Cardoso. Todavia, sua morte prematura por ataque cardíaco em 1998 privou o conservadorismo de uma importante liderança. A segunda ocasião foi a já referida pré-candidatura de Roseana Sarney, ceifada no nascimento. Em resumo: de um poderoso caudatário do PSDB durante oito anos, o PFL se tornou um partido conservador sem força nacional em 2002, tendo sua condição piorada ainda mais depois disto, ao amargar a quase inaudita condição de partido alijado do poder nacional - afinal, suas lideranças deram sustentação a todos os governos desde a implantação do regime militar, em 1964, perfazendo quase quarenta anos de situacionismo ininterrupto.

Mas se o governo Lula afastou o PFL (ou seu sucedâneo, o DEM) dos cargos governamentais, dando-lhe a oportunidade de ser oposição no plano federal, logrou por outro lado atrair para seu interior uma série de outras agremiações do campo conservador brasileiro. Um campo que, note-se, caracteriza-se como conservador menos por constituir-se de partidos e lideranças consistentemente orientados à direita do ponto de vista ideológico, e mais por reproduzir padrões de comportamento político profundamente arraigados nas tradições patrimonialistas da política brasileira. Os partidos de direita no Brasil correspondem à maior parte das agremiações que podemos denominar como partidos de adesão, embora o maior dentre os partidos com esta característica seja uma organização de centro, o PMDB. Defino como partidos de adesão aquelas organizações que, carecendo de um conteúdo programático consistente e/ou de um projeto de poder autônomo no plano nacional no qual figurem como protagonistas ou parceiros preferenciais de uma agremiação mais destacada, optam então por aderir ao governo do dia, qualquer que seja sua orientação programática ou ideológica mais geral.

Os partidos de adesão certamente não têm como participar de governos de orientação extremista, mas estes são muito improváveis no presidencialismo de coalizão brasileiro (Abranches, 1988; Figueiredo \& Limongi, 1999; Amorim Neto 
\& Tafner, 2002), pois para governar num sistema partidário muito fragmentado, os presidentes brasileiros precisam necessariamente construir amplas coalizões partidárias de sustentação no Legislativo, o que lhes obriga a compor interesses, moderar propostas e dirimir divergências. Segundo Kinzo (2004: 32) o número efetivo de partidos brasileiros resultante das eleições de 2002 foi de 8,5; se tomarmos a composição da Câmara dos Deputados resultante daquele pleito, o maior partido, o PT, obteve apenas $17,7 \%$ das cadeiras - muito distante não apenas da maioria absoluta, mas sobretudo da maioria de $60 \%$ necessária para emendar a constituição, algo indispensável aos governos no Brasil, tendo em vista a Carta de 1988 conter muitas políticas públicas de caráter ordinário (Couto \& Arantes, 2003; 2006; Arantes \& Couto, 2009).

Por isto, Lula teve de compor uma coalizão inicial de nada menos que 12 partidos, a qual, após algumas defecções e readesões, chegou ao final do segundo mandato com 16 agremiações - algumas delas bem pequenas, a bem da verdade (ver tabela). Apenas quatro partidos no Legislativo posicionavam-se de forma abertamente contrária ao governo, detendo $25 \%$ das cadeiras na Câmara e $32 \%$ do Senado: PSDB, DEM, PPS e PSOL - este último uma dissidência à esquerda do PT, de diminutas dimensões parlamentares. As três primeiras agremiações, por sua vez, atuaram como uma frente razoavelmente unificada de oposição, posicionada à direita do governo Lula, logrando também se coligar nas eleições de 2006 e 2010 à Presidência da República e a governador de alguns estados, como o Rio de Janeiro, São Paulo e Minas Gerais. Foram raras, contudo, as derrotas parlamentares que a oposição logrou impor ao governo, as quais, quando ocorreram, deveram-se principalmente a divisões no interior da própria base governista.

De qualquer modo, a aliança do PT com partidos à sua direita, dentre os quais o principal é o PMDB, significou uma inflexão ao centro, posicionando o partido e seu governo à centro-esquerda. $\mathrm{O}$ coroamento deste processo foi a aliança entre PMDB e PT para as eleições presidenciais de 2010, a qual se replicou em diversas disputas estaduais nas quais o PT abdicou da indicação de um candidato a governador, apoiando um nome peemedebista como contrapartida à sustentação que o parceiro lhe emprestou no nível nacional, indicando o candidato a vice-presidente, o próprio presidente do partido, Michel Temer. Considerando-se a capilaridade peemedebista país afora e o tempo de rádio e televisão na propaganda política -assegurado com base no tamanho das bancadas partidárias na Câmara dos Deputados- a barganha mostrava-se interessante para o PT. Além disto, reforçava o compromisso entre as duas agremiações para uma futura composição governamental, em caso da vitória da candidata petista.

Todavia, a guinada do PT e de Lula rumo ao centro não decorreu apenas da necessidade de construir uma coalizão parlamentar majoritária (ou ultramajoritária, considerando-se o quorum constitucional de 3/5). Ela também foi causada por dois outros processos. O primeiro deles, de longo curso, foi a transformação pela qual passou o partido ao longo de suas diversas experiências de governo nos níveis municipal e estadual. O desafio de ser governo, abandonando a condição originária de mero opositor a tudo e a todos tornou o PT um partido mais pragmático, 
pluralista e afeito à negociação política (Couto, 1995). Assim, quando chegou ao governo federal, a agremiação já apresentava um longo histórico de experiências governamentais caracterizadas pela moderação, de maneira que sua postura de centro-esquerda no governo do país não era uma novidade.

Tabela

Composição do Congresso Nacional - 2008

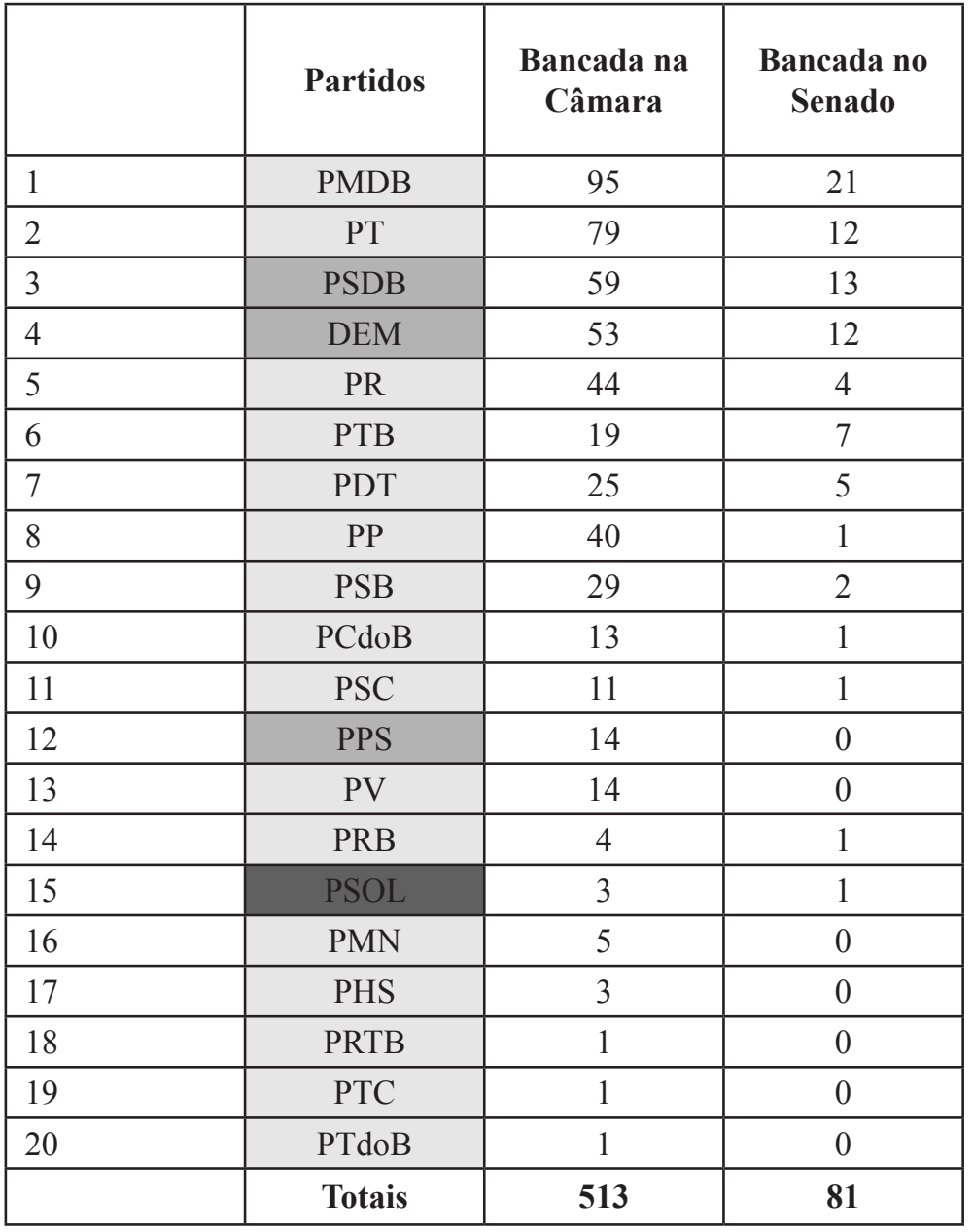

Fontes: Câmara dos Deputados e Senado Federal.

O segundo processo, que não se distingue por completo do primeiro, foi a percepção de diversas lideranças petistas da necessidade de levar a cabo uma política econômica confiável para o mercado, com vistas a evitar os riscos da fuga de capi- 
tas e da greve de investimentos. O primeiro sinal dado para esse processo de confidence building foi a já mencionada "Carta ao Povo Brasileiro". Mas, para além dele, contaram também a indicação de um homem do mercado para a presidência do Banco Central (o ex-chairman do Bank Boston, Henrique Meirelles), o apoio a um acordo do governo Fernando Henrique Cardoso com o Fundo Monetário Internacional (FMI) e medidas iniciais de caráter ainda mais ortodoxo do que as que vinham sendo adotadas pela gestão do PSDB - como a elevação da taxa de juros e a fixação de um superávit fiscal primário mais elevado do que o até então adotado.

O que permite afirmar que este processo de adoção de uma política econômica de corte conservador não se distingue totalmente da mudança provocada pelas experiências governamentais no plano subnacional é o fato de que as gestões petistas sempre se caracterizaram pela austeridade financeira. Assim, havia uma dissonância entre a prática governamental efetiva do PT e o discurso radical do partido contra o pagamento das dívidas, os acordos com o FMI, a Lei de Responsabilidade Fiscal $^{9}$ e outras medidas similares. Na realidade, tratava-se de um discurso voltando tanto à satisfação dos devaneios ideológicos do público interno quanto ao reforço da reputação de oposição a tudo e a todos que o PT firmara desde a sua origem.

\section{Considerações Finais}

Os oito anos do governo de Luís Inácio Lula da Silva significaram, ao mesmo tempo, o culminar de um longo processo histórico e um momento de importante ruptura na política brasileira. O processo histórico que culmina na gestão petista é a consolidação democrática brasileira, não só em função da tranquila transferência de poder entre dois presidentes de partidos adversários e da chegada de uma nova elite ao poder, como também em decorrência da capacidade demonstrada pelo sistema político brasileiro de permitir que um presidente de esquerda exercesse seu mandato sem qualquer tipo de questionamento à sua legitimidade - uma novidade na história do país. ${ }^{10}$ Acrescente-se ainda que ao final do governo Lula o sistema partidário brasileiro parece ter adquirido uma feição razoavelmente nítida e consolidada, na qual PT e PSDB aparecem como as duas principais agremiações no plano nacional, polarizando as disputas presidenciais num antagonismo entre centro-esquerda e centro, respectivamente. Nesse cenário, a direita partidária vêse bastante fragilizada como força política nacional, tornando os tucanos o desaguadouro natural do eleitorado mais conservador, por absoluta falta de alternativa - já que o PSDB não pode ser propriamente considerado um partido de direita, apesar da feição elitizada de seus quadros diretivos. Em torno dos dois principais partidos gravita um grupo de agremiações que, embora muitas vezes fortes em alguns estados, são pouco capazes de operar de forma autônoma e competitiva nas disputas presidenciais. Ao redor do PT aparecem os médios e pequenos partidos de esquerda dotados de alguma relevância: PSB, PDT e PC do B; ao redor do PSDB, um partido conservador, o DEM, e um partido de centro-esquerda, o PPS. Afora eles, temos o grande número de partidos de adesão enumerados na tabela, dentre 
os quais se destaca o centrista PMDB - parceiro indispensável (e sempre disponível) para qualquer governo.

Já a ruptura representada pela administração petista se dá em duas frentes, uma política, outra econômica. A ruptura política diz respeito ao fim de uma competição centrada na oposição entre presumidos "éticos" e "não éticos" na política nacional, ou entre "honestos" e "desonestos". A sucessão de escândalos de corrupção que assolou todos os principais partidos deixou-os sem condições efetivas de apresentarem-se ao eleitorado como os únicos dignos de confiança, num mundo marcado pela vilania dos demais. Isto não quer dizer, entretanto, que o debate acerca do combate a corrupção foi abandonado, mas sim que sua retomada terá de ocorrer num patamar mais elaborado do que a mera contraposição entre declarações insinceras acerca da honestidade dos contendores; será preciso propor formas efetivas e eleitoralmente convincentes de lidar com este problema.

Já a ruptura econômica diz respeito, sobretudo, à significativa redução da pobreza e da desigualdade no Brasil durante os anos de Lula (Neri, 2007). Embora a melhoria da situação econômica dos mais pobres já tenha começado no governo de Fernando Henrique Cardoso, com o fim da alta inflação, foi durante o governo Lula que essa melhora apresentou uma inflexão mais significativa - sobretudo no que concerne à redução da desigualdade. E esta não é uma transformação de pouca importância num país com o histórico de abissal desigualdade que apresenta o Brasil. Esta melhora, sem sombra de dúvida, foi o fator fundamental a impulsionar não somente a altíssima popularidade do presidente petista, mas também a candidatura de sua sucessora nas eleições de 2010 .

\section{Referencias}

1. Ver Pareto (1966).

2. Ver Gramsci (1984); Braga (2010).

3. Também W. Hunter e T. Power (2007) analisam a inversão eleitoral promovida pelo governo Lula, focando-se nos resultados eleitorais de 2006.

4. O escândalo do "mensalão" foi deflagrado com as denúncias feitas por Roberto Jefferson sobre um suposto pagamento mensal feito pelo governo a parlamentares que apoiassem seus projetos no Legislativo. O que de fato se comprovou depois foi que parlamentares da base aliada, mas principalmente do próprio $\mathrm{PT}$, recebiam do partido somas consideráveis de dinheiro originado em empréstimos feitos com a intermediação de um publicitário, Marcos Valério de Souza. A alegação do PT é que os recursos se destinavam a cobrir despesas de campanha do partido e seus aliados, de forma ilegal - o chamado "caixa 2" eleitoral.

5. Apesar do seu nome, pode-se dizer que o Partido Liberal quase nada tinha de mais propriamente doutrinário e afim com o liberalismo, seja político, seja econômico, em qualquer uma de suas variantes. Tratava-se, simplesmente, de um partido de orientação tradicional, vocacionado à adesão aos governos.

6. Até mesmo dentre os candidatos de pouca relevância, os chamados "nanicos", figuraram apenas nomes da esquerda, no caso, a trotskista: Zé Maria, pelo Partido Socialista dos Trabalhadores Unificado (PSTU) e, Rui Costa Pimenta, pelo Partido da Causa Operária (PCO).

7. Para a discussão deste ponto veja-se a análise de V. Marchetti \& R. Cortez (2009). Segundo os autores, o STF tende sistematicamente a confirmar as decisões do TSE, pois a corte eleitoral opera, na prática, como uma antecâmara do Supremo Tribunal para assuntos eleitorais. 
8. Esse entendimento dos tribunais superiores foi depois contrarrestado pela Emenda Constitucional $\mathrm{n}^{\circ}$ 52, que inseriu na Constituição Federal a seguinte norma: "É assegurada aos partidos políticos autonomia para definir sua estrutura interna, organização e funcionamento e para adotar os critérios de escolha e o regime de suas coligações eleitorais, sem obrigatoriedade de vinculação entre as candidaturas em âmbito nacional, estadual, distrital ou municipal, devendo seus estatutos estabelecer normas de disciplina e fidelidade partidária". Todavia, essa explicitação da liberdade eleitoral dos partidos só passou a valer a partir das eleições de 2010, pois foi aprovada a menos de um ano das eleições de 2006 e, portanto, não poderia vigorar naquele pleito em função do princípio da anualidade, segundo o qual modificações da legislação eleitoral apenas vigoram quando sancionadas com pelo menos um ano de antecedência das eleições.

9. A Lei de Responsabilidade Fiscal (LRF) é, na verdade, a Lei Complementar $n^{\circ} 101$, de maio de 2000. Nos termos do próprio Tesouro Nacional, trata-se de uma lei que "estabelece normas de finanças públicas voltadas para a responsabilidade na gestão fiscal, mediante ações em que se previnam riscos e corrijam desvios capazes de afetar o equilíbrio das contas públicas, destacando-se o planejamento, o controle, a transparência e a responsabilização como premissas básicas" (http://www.tesouro.fazenda. gov.br/hp/lei_responsabilidade_fiscal.asp). Aprovada no segundo mandato de Fernando Henrique Cardoso, ela sempre sofreu a oposição do PT, mas permaneceu intocada durante os oito anos do governo Lula.

10. Ver Marenco (2007).

\section{Bibliografía}

S. ABRANCHES (1988), "Presidencialismo de coalizão: o dilema institucional brasileiro", in Dados. Revista de ciências sociais, Vol. 31, N 1 .

O. AMORIM NETO \& P. TAFNER (2002), "Governos de coalizão e mecanismos de alarme de incêndio no controle legislativo das medidas provisórias", in Dados. Revista de ciências sociais, Vol. 45, No 4 . R. B. ARANTES \& C. G. COUTO (2009), "Uma constituição incomum”, in M. A. R. CARVALHO; C. ARAUJO \& J. A.SIMÕES (Org.), A constituição de 1988: passado e futuro, São Paulo, Aderaldo \& Rothschild (Hucitec), ANPOCS.

R. BRAGA (2010), "Movimentos sociais na era Lula", Cult, No 148, Julho.

C. G. COUTO \& R. B. ARANTES (2006), "Constituição, governo e democracia no Brasil”, in Revista Brasileira de Ciências Sociais, São Paulo, Vol. 21, № 61.

- (2003). “¿Constitución o políticas públicas? Una evaluación de los años FHC", in V. PALERMO (Comp.), Politica brasileña contemporánea: de Collor a Lula en años de transformación, Buenos Aires, Instituto Di Tella - Siglo Veintiuno Editores.

C. G. COUTO (1995), O desafio de ser governo: o PT na Prefeitura de São Paulo (1989-1992), Rio de Janeiro, Paz e Terra.

A. FIGUEIREDO \& F. LIMONGI (1999), Executivo e Legislativo na nova ordem constitucional, Rio de Janeiro, Editora FGV.

A. GRAMSCI (1984), Maquiavel, a política e o Estado moderno, 5 a edição, Rio de Janeiro, Civilização Brasileira.

W. HUNTER \& T. POWER (2007), "Recompensando Lula: poder executivo, política social e as eleições brasileiras de 2006" in M. ALCÁNTARA SÁEZ \& C. R. MELO, A democracia brasileira: balanço e perspectivas para o século 21, Belo Horizonte, Editora UFMG.

M. D. KINZO (2004), "Partidos, eleições e democracia no Brasil pós-1985", in Revista Brasileira de Ciências Sociais, Vol. 19, № 54, fevereiro.

V. MARCHETTI \& R. CORTEZ (2009), “A Judicialização da competição política: o TSE e as coligações eleitorais", in Opinião Pública, Vol. 15, No 2. Disponível em: http://www.scielo.br/pdf/op/ v15n2/06.pdf.

A. MARENCO (2007), "Devagar se vai ao longe? A transição para a democracia no Brasil em perspectiva comparada”, in M. ALCÁNTARA SÁEZ \& C. R. MELO, A democracia brasileira: balanço e perspectivas para o século 21, Belo Horizonte, Editora UFMG.

M. NERI (2007), "Poverty, income and income policies: Lula's Real", in Ensaios Econômicos, Rio de 
Janeiro, Escola de Pós-Graduação em Economia da Fundação Getúlio Vargas, dezembro.

V. PARETO (1966), "As elites e o uso da força na sociedade", in A. DE SOUZA, Sociologia política, Rio de Janeiro, Zahar.

A. SINGER (2009), "Raízes sociais e ideológicas do lulismo", in Novos Estudos, No 85, novembro.

Recibido: 15/06/2010. Aceptado: 20/08/2010.

Cláudio Gonçalves Couto, "Hacia el centro: el PT y el gobierno de Lula en Brasil". Revista Temas y

Debates. ISSN 1666-0714, año 14, número 20, octubre 2010, pp 125-139. 